\title{
PENERAPAN OPTIMASI PSO UNTUK MENINGKATKAN AKURASI ALGORTIMA ID3 PADA PREDIKSI PENYAKIT IBU HAMIL
}

\author{
Agus Byna \\ Univeristas Sari Mulia \\ Jalan Pramuka No. 02 \\ e-mail: agusbyna@unism.ac.id
}

\begin{abstract}
ABSTRAK
Industri di bidang kesehatan saat ini memiliki sejumlah pusat data yang besar, dari beberapa data sebagian belum dioptimalkan dalam pengolahannya, sehingga informasi didapat tidak dapat di jadikan referensi di dalam pengambilan keputusan oleh pakar di bidang kesehatan. Pre eklampsia pada ibu hamil adalah satu penyakit ibu hamil yang perlu di waspadai di Indonesia karena menjadi penyebab utama kematian ibu dan janin. Penggunaan Data Mining dalam memprediksi sangat diperlukan sehingga praktisi kesehatan dapat dengan mudah dalam pengambilan keputusan. Diperolehnya informasi dalam menerapkan optimasi particle swarm optimization pada algoritma ID3 (Iterative Dichotomiser Three) untuk meningkatkan keakuratan dalam memprediksi penyakit pre eklampsia pada ibu hamil. Algoritma Decision Tree salah satunya ID3, dapat digunakan untuk memprediksi penyakit Pre Eklamsia. Namun masih ada ruang untuk meningkatkan akurasi, yaitu dengan mengoptimasi algoritma ID3 dengan Particle Swarm Optimization (PSO). Data latih dan testing menggunakan dua metode yang pertama adalah Algoritma ID3 kemudian Algoritma ID3 menggunakan optimasi Particle Swarm Optimization (PSO) dari kedua hasil tersebut didapat yang pertama Algoritma ID3 dengan tingkat akurasi sebesar 90.62\% dan AUC sebesar 0.857 menghasilkan diagnosanya adalah Good Classification, hasil yang kedua didapatkan tingkat akurasi sebesar 93.33\% dengan AUC sebesar 0,906 dari Algortima ID3 dengan optimasi Particle Swarm Optimization hasil tingkat diagnosanya adalah diagnosa Excelent Classification. Dari hasil kedua metode memiliki perbedaan mulai dari tingkat akurasi 3,07\% kemudian AUC 0,049.
\end{abstract}

Kata Kunci: Klasifikasi, ID3, PSO, Pre Eklampsia.

\begin{abstract}
The industry in the health sector currently has a large number of data centers, some of which have not been optimized for processing, so that the information obtained cannot be made a reference in making decisions by experts in the health sector. Pre-eclampsia in pregnant women is a disease of pregnant women who need to be alerted in Indonesia because it is a major cause of maternal and fetal death. The use of Data Mining in predicting is indispensable so that health practitioners can easily make decisions. Obtained information in implementing particle swarm optimization on the ID3 (Iterative Dichotomiser Three) algorithm to improve accuracy in predicting preeclampsia in pregnant women. The Decision Tree algorithm, one of which is ID3, can be used to predict Pre-Eclampsia. But there is still room to improve accuracy, namely by optimizing the ID3 algorithm with Particle Swarm Optimization (PSO). Training and testing data using the first two methods are ID3 Algorithm then ID3 Algorithm using Particle Swarm Optimization (PSO) optimization of the two results obtained the first ID3 Algorithm with an accuracy rate of $90.62 \%$ and AUC of 0.857 resulting in the diagnosis is Good Classification, the results of which are the second obtained an accuracy rate of 93.33\% with an AUC of 0.906 from Algorithm ID3 with Particle Swarm Optimization results of the diagnosis level is the Excellent Classification diagnosis. From the results of the two methods have differences ranging from an accuracy level of $3.07 \%$ then AUC of 0.049 .
\end{abstract}

Keywords: Classification, ID3, PSO, Pre-Eclampsia.

\section{PENDAhUluan}

$\mathrm{U}$ sia kehamilan sekitar 20 minggu atau lebih memiliki tanda-tanda edema di selingi roteinuria dan juga hipertensi yang terjadi karena primigravida pada rahim pertama kalinya mendapatkan proses pembuahan yang memberikan efek terhadap kehamilan gejala yang biasanya disebut Pre Eklamsia. Dari reaksi tersebut seorang wanita menderita Pre janinnya[1].

Pre eklampsia pada ibu hamil adalah satu penyakit yang perlu di waspadai di Indonesia karena menjadi penyebab utama kematian ibu. Karena kasus tersebut untuk memprediksi penyakit pre eklamsia dengan memanfaatkan data mining untuk klasifikasi agar memudahkan para pakar di bidang kesehatan dapat melakukan keputusan yang lebih cepat dan tepat sehingga menjadi akurat.

Algoritma ID3 adalah algoritma digunakan untuk melatih dataset untuk mendapatkan pengetahuan yang diwakili oleh pohon keputusan yang diambil dan disajikan dalam bentuk aturan IF -THEN. Jika satu set aturan prediksi diekstraksi dari algoritma ID3 dan efisiensi model yang dihasilkan [2]. 
Dengan meningkatkan hasil akurasi maka dilakukan debfab menggunakan penambahan optimasi sehingga dalam mendeteksi penyakit jantung mendapatkan hasil yang lebih akurat, dengan menggunakan metode algortima Naïve Bayes dengan optimasi PSO sehingga hasilnya bisa menjadi perbandingan dengan hasil laboratorium [3].

\section{LANDASAN TEORI}

\section{A. Pre Eklamsia}

Gejala pre eklamsia memiliki tanda-tanda hipertensi diselingi dengan edema dan proteinurine yang muncul ini biasanya terjadi triwulan ketiga atau sebelumnya pada saat kehamilan (kehamilan abnormal)[1].

Gejala Pre eklamsia terjadi kepada ibu hamil, setelah bersalin serta dalam keadaan masa nifas yang terdiri tiga tahapan atau biasa disebut dengan trias yaitu hipertensi, proteinurin dan pembengkakan pada kaki, kadang-kadang disertai kejang-kejang hingga koma, karena tidak menunjukkan adanya kelainan vaskuler atau hiertensi sebelumnya [4].

\section{B. Data Mining}

Menggali nilai dari sekumpulan data atau biasanya disebut sebagai proses menambang pengetahuan menggunakan beberapa metode dari sekumpulan data yang besar (database) sehingga hasil pengetahuan tersebut dapat digunakan kembali menjadi sebuah informasi yang berguna [5].

\section{ID3}

Iterative Dichotomizes 3 (ID3) merupakan turunan yang paling dasar dari algoritma decision tree learning (algoritma pembelajaran pohon keputusan). Fungsi dari penggunaan algortima ini sebagai pencarian secara menyeluruh sehingga menghasilkan semua kemungkinan pada pohon keputusan. Algoritma ini dikembangkan oleh J.Ross Quinlan dalam mengimplementasi penggunaan secara rekursif. Hasil dari algortima ini adalah membangun pohon keputusan dari atas ke bawah, sebagai contoh: "atribut mana yang pertama kali harus koreksi kemudian diletakkan pada akar (root) dari contoh tersebut dapat di evaluasi semua atribut yang ada dapat menggunakan suatu ukuran statistik (yang sering digunakan adalah information gain) dalam mengukur efektivitas dan efisiensi dari salah satu atribut dalam mengklasifikasikan kumpulan sampel data [5].

\section{Particle Swarm Optimization (PSO)}

PSO (Particle Swarm Optimization) merupakan salah satu metode optimasi terbaik dalam melakukan klasifikasi dikembangkan pada tahun 1995 oleh 2 orang yaitu Eberhart dan Kennedy, mereka terinpirasi melalui perilaku sosial hewan yaitu sekelompok burung atau ikan. PSO sendiri dipengaruhi oleh sifat individu kelompok dalam melakukan pencarian solusi yang optimal. Sebagai contoh persoalan optimasi $d$-variabel yang disebar dengan kawanan partikel (misalkan sebanyak n-partikel) di dalam ruang $d$-dimensi secara acak. Keunggulan dari beberapa partikel meruapakan kandidat solusi yang berisi nilai fitness tertentu. Kemudian tiap partikel akan bergerak dengan kecepatan tertentu yang dipengaruhi oleh pengalaman terbang sendiri ataupun pengalaman partikel lain [5].

\section{HASIL DAN PEMBAHASAN}

\section{A. Penerapan Algoritma ID3}

Untuk algoritma ID3, uji coba yang dilakukan adalah untuk membentuk pola pohon keputusan (decision tree). Dibawah ini digambarkan bagaimana bentuk pola peletakan algoritma ID3 di Rapid Miner untuk menampilkan bentuk pola pohon keputusan (decision tree). Penerapan algortima ID3 menggunakan information_gain, karena hasil yang didapat adalah bentuk pohon keputusan yang sempurna seperti gambar berikut:

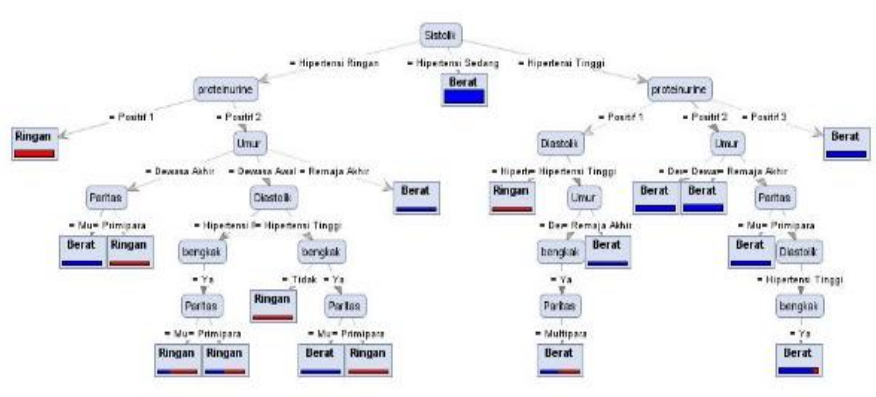

Gambar 1 Pohon Keputusan hasil dari Algoritma ID3 
Penjelasan pada Gambar 1 adalah pada root sistolik jika nilai hipertensi ringan dan proteinurine = positif 1 maka hasil dari daun atau class = ringan. Rincian lengkap dari Gambar 1 dapat dilihat dari aturan pohon keputusan sebagai berikut:

R1 : IF Sistolik $=$ Hipertensi Ringan and proteinurine $=$ Positif 1 then Ringan

R2 : IF Sistolik $=$ Hipertensi Ringan and proteinurine $=$ Positif 2 and Umur $=$ Dewasa Akhir and Paritas $=$ Multipara then Berat

R3 : IF Sistolik $=$ Hipertensi Ringan and proteinurine $=$ Positif 2 and Umur $=$ Dewasa Akhir and Paritas $=$ Primipara then Ringan

R4 : IF Sistolik $=$ Hipertensi Ringan and proteinurine $=$ Positif 2 and Umur $=$ Dewasa Awal and Diastolik $=$ Hipertensi Ringan and bengkak $=$ Ya and Paritas $=$ Multipara then Ringan

R5 : IF Sistolik $=$ Hipertensi Ringan and proteinurine $=$ Positif 2 and Umur $=$ Dewasa Awal and Diastolik $=$ Hipertensi Ringan and bengkak $=$ Ya and Paritas $=$ Primipara then Ringan

R6 : IF Sistolik $=$ Hipertensi Ringan and proteinurine $=$ Positif 2 and Umur $=$ Dewasa Awal and Diastolik $=$ Hipertensi Tinggi and bengkak $=$ Tidak then Ringan

R7 : IF Sistolik $=$ Hipertensi Ringan and proteinurine $=$ Positif 2 and Umur $=$ Dewasa Awal and Diastolik $=$ Hipertensi Tinggi and bengkak $=$ Ya and Paritas $=$ Multipara then Berat

R8 : IF Sistolik $=$ Hipertensi Ringan and proteinurine $=$ Positif 2 and Umur $=$ Dewasa Awal and Diastolik $=$ Hipertensi Tinggi and bengkak $=$ Ya and Paritas $=$ Primipara then Ringan

R9 : IF Sistolik $=$ Hipertensi Ringan and proteinurine $=$ Positif 2 and Umur $=$ Remaja Akhir then Berat

R10 : IF Sistolik $=$ Hipertensi Sedang then Berat

R11 : IF Sistolik $=$ Hipertensi Tinggi and proteinurine $=$ Positif 1 and Diastolik $=$ Hipertensi Sedang then Ringan

R12 : IF Sistolik $=$ Hipertensi Tinggi and proteinurine $=$ Positif 1 and Diastolik $=$ Hipertensi Tinggi and Umur $=$ Dewasa Akhir and bengkak $=$ Ya and Paritas $=$ Multipara then Berat

R13 : IF Sistolik $=$ Hipertensi Tinggi and proteinurine $=$ Positif 1 and Diastolik $=$ Hipertensi Tinggi and Umur $=$ Remaja Akhir then Berat

R14 : IF Sistolik $=$ Hipertensi Tinggi and proteinurine $=$ Positif 2 and Umur $=$ Dewasa Akhir then Berat

R15 : IF Sistolik $=$ Hipertensi Tinggi and proteinurine $=$ Positif 2 and Umur $=$ Dewasa Awal then Berat

R16 : IF Sistolik $=$ Hipertensi Tinggi and proteinurine $=$ Positif 2 and Umur $=$ Remaja Akhir and Paritas $=$ Multipara then Berat

R17 : IF Sistolik $=$ Hipertensi Tinggi and proteinurine $=$ Positif 2 and Umur $=$ Remaja Akhir and Paritas $=$ Primipara and Diastolik $=$ Hipertensi Tinggi and bengkak $=$ Ya then Berat

R18 : IF Sistolik $=$ Hipertensi Tinggi and proteinurine $=$ Positif 3 then Berat

\section{B. Hasil Pengujian Menggunakan Algoritma ID3}

Hasil dari uji coba yang dilakukan yaitu menggunakan hasil confusion matrix terbentuk sebuah matrix yang terdiri true positif atau tupel positif dan true negatif atau tupel negatif, setelah itu tinggal memasukan data testing yang persiapkan kedalam model confusion matrix dengan menggunakan ten fold validation (X-Validation) maka didapatkan hasilnya adalah accuracy dan AUC (Area Under Curve).

Tabel 1 Hasil Akurasi Algoritma ID3

\begin{tabular}{|c|c|c|c|}
\hline Accuracy : 90.62 \% \\
\hline & $\begin{array}{l}\text { True Be- } \\
\text { rat }\end{array}$ & True Ringan & Class precision \\
\hline Pred. Berat & 115 & 9 & $92.84 \%$ \\
\hline Pred. Ringan & 5 & 20 & $80 \%$ \\
\hline Class recall & $95.83 \%$ & $68.97 \%$ & \\
\hline
\end{tabular}


Hasilnya terlihat pada tabel 1adalah jumlah True Positive (TP) sebanyak 115, dan untuk False Positif(FP) sebanyak 5, untuk True Negatif (TN) sebanyak 9, dan untuk False Negative (TN) sebanyak 20. Hasil data yang terdapat pada confusion matrix diatas maka nilai accuracy menunjukan bahwa algoritma ID3 adalah sebesar $90.62 \%$.

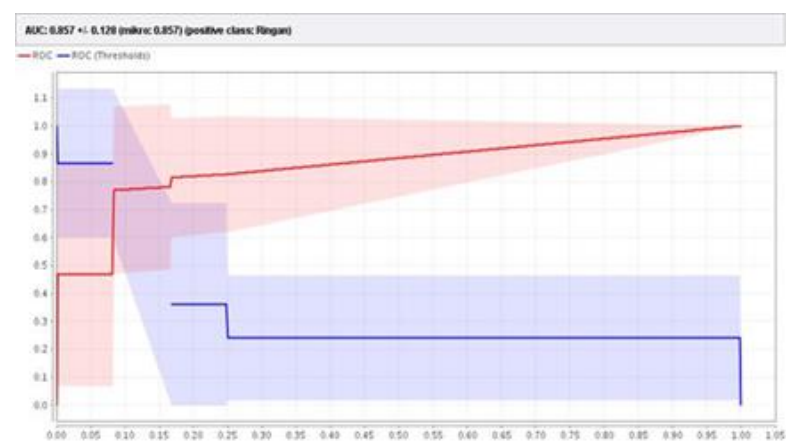

Gambar 2 Nilai AUC dalam grafik ROC algoritma ID3

Gambar 2 menjelaskan hasil nilai AUC (Area Under Curve) yang didapat dari pengolahan ROC untuk algoritma ID3 dengan menggunakan data training sebesar 0.857 sehingga tingkat diagnosa adalah good classification.

\section{Hasil Pengujian Menggunakan Algortima ID3 berbasis PSO}

Pada tabel 2 di bawah merupakan hasil pengujian yang sudah di optimasi menggunakan PSO terlihat hasil jumlah True Positive (TP) sebanyak 120, untuk False Positif (FP) sebanyak 0, untuk True Negatif (TN) sebanyak 10, dan untuk False Negative (FN) sebanyak 19. Hasil data yang telah di optimasi terdapat pada confusion matrix ,nilai accuracy adalah sebesar $93.33 \%$.

Tabel 2 Hasil Akurasi Algoritma ID3 berbasis PSO

\begin{tabular}{|l|c|c|l|}
\hline \multicolumn{2}{|c|}{ Accuracy : 93.33 \% } & True Berat & $\begin{array}{l}\text { Class } \\
\text { precision }\end{array}$ \\
\hline Pred. Berat & 120 & 10 & $92.31 \%$ \\
\hline Pred. Ringan & 0 & 19 & $100 \%$ \\
\hline Class recall & $100 \%$ & $65.52 \%$ & \\
\hline
\end{tabular}

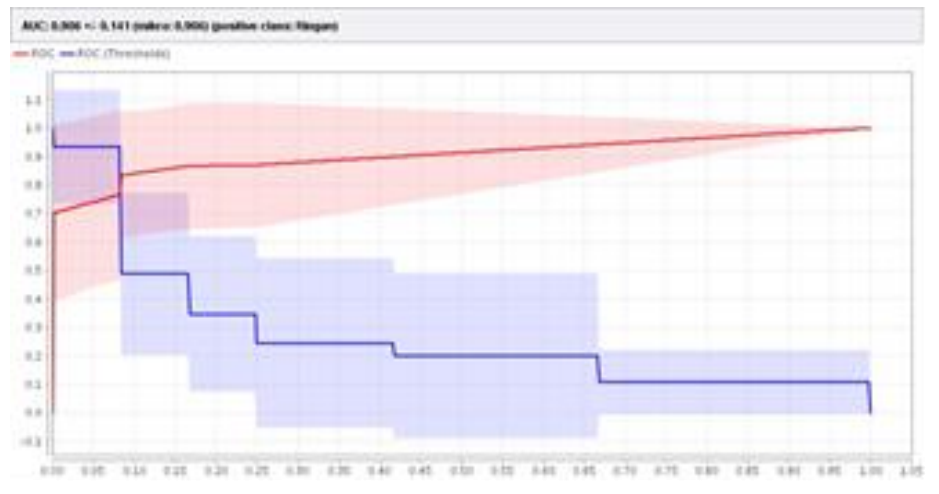

Gambar 3 Nilai AUC dalam grafik ROC algoritma ID3 berbasis PSO

Hasil nilai AUC (Area Under Curve) yang didapat dari pengolahan ROC untuk algoritma ID3 di optimasi dengan PSO sebesar 0.906 dapat dilihat pada gambar 3 dengan tingkat diagnosa excellent classification. 


\section{Analisa Evaluasi Dan Validasi Hasil}

Dari Analisa diatas kemudian di evaluasi dengan menggunakan confusion matrix dan ROC curve terlihat hasil yang ujikan dengan penggunaan Algortima ID3 tanpa di optimasi dan Algortima ID3 dengan Optimasi PSO dengan tabel 3 di bawah ini:

Table 3 Hasil Pengujian Algoritma ID3 dan ID3 berbasis PSO

\begin{tabular}{|l|l|c|}
\hline & Akurasi & AUC \\
\hline Algortima ID3 & $90.62 \%$ & 0.857 \\
\hline $\begin{array}{l}\text { Algortima ID3 } \\
\text { Berbasis } \\
\text { PSO }\end{array}$ & $93.33 \%$ & 0.906 \\
\hline
\end{tabular}

Evaluasi hasil akurasi untuk Algortima ID3 adalah 90.62\% dan nilai AUC sebesar 0.857 menghasilkan nilai diagnosa Good Classification, kemudian hasil dari Algortima ID3 yang di optimasi dengan PSO adalah 93.33\% dan nilai AUC sebesar 0.906 nilai diagnosa Excelent Classification, selisih nilai keduanya untuk akurasi sebesar $3.07 \%$ dan untuk nilai AUC sebesar 0.049.

\section{KESIMPULAN}

Dari hasil kedua metode tersebut terlihat ada sedikit perbedaan baik dalam nilai akurasi dan AUC, dari perbedaan tersebut terjadi karena Algoritma ID3 dapat di optimasi menggunakan PSO sehingga terdapat hasil perbedaan nilai akurasi sebesar 3.07\% dan AUC sebesar 0.049. Jadi dapat disimpulkan bahwa penerapan teknik optimasi PSO dapat meningkatkan nilai akurasi dan AUC pada algoritma ID3.

\section{DAFTAR PUSTAKA}

[1] LEMOINE, Elizabeth; THADHANI, Ravi. Affordable Preeclampsia Therapeutics. Trends in pharmacological sciences, 2019 , 40.2 : 85-87.

[2] Ganggayah, Mogana Darshini, et al. "Predicting factors for survival of breast cancer patients using machine learning techniques." BMC medical informatics and decision making 19.1 (2019): 48.

[3] Jusia, Pareza Alam. "ANALISIS KOMPARASI PEMODELAN ALGORITMA DECISION TREE MENGGUNAKAN METODE PARTICLE SWARM OPTIMIZATION DAN METODE ADABOOST UNTUK PREDIKSI AWAL PENYAKIT JANTUNG." Seminar Nasional Sistem Informasi (SENASIF). Vol. 2. No. 1. 2018.

[4] Yuliani, Diki Retno, et al. "TERAPI MUROTTAL SEBAGAI UPAYA MENURUNKAN KECEMASAN DAN TEKANAN DARAH PADA IBU HAMIL DENGAN PREEKLAMPSIA: LITERATURE REVIEW DILENGKAPI STUDI KASUS." Jurnal Kebidanan 8.2 (2018): $79-98$.

[5] Eldén, Lars. Matrix methods in data mining and pattern recognition. Vol. 15. SIAM, 2019. 
JTIULM - Volume 04, Nomor 2, Oktober 2019: 65 - 70 